\section{Configuração das pregas vestibulares à fonação em adultos com e sem disfonia}

\author{
Marcos Antônio Neme $z^{1}$, Paulo Augusto de Lima \\ Pontes², Vanessa Pedrosa Vieira 3 , \\ Reinaldo Kazuo Yazaki ${ }^{4}$
}

\section{Vestibular fold configurantion during phonation in adults with and without dysfonia}

Palavras-chave: voz, laringe, prega vestibular, laringoscopia. Key words: voice, larynx, vestibular fold, laryngoscopy.

\section{Resumo / Summary}

\begin{abstract}
A
pregas vestibulares participam da emissão vocal com mudanças evidentes de posição e forma durante este processo, porém pouco ou quase nada se conhece sobre o significado desta participação e como se iniciam estes movimentos ativos que mudam sua forma e contorno. Entendemos que o conhecimento da participação das pregas vestibulares na fisiologia laríngea possa ter importante aplicação prática, pois permitirá avaliar melhor o comprometimento funcional em condições patológicas, o que auxiliará na definição de estratégias para 0 adequado tratamento. Objetivo: Estudar a configuração da prega vestibular durante a fonação (emissão sustentada do $/ \mu /$ ) comparando exames de indivíduos sem queixa vocal (grupo eufonia) com portadores de queixa de voz (grupo disfonia). Forma de Estudo: Coorte transversal simples. Material e Método: Foram analisados 120 registros de imagens de laringes, sendo 60 de indivíduos eufônicos e 60 de disfônicos, constituído cada grupo de igual número de indivíduos em relação ao gênero. Foi identificada a posição da borda livre de prega vestibular em relação a uma reta que une as inserções anterior e posterior da mesma. Na dependência desta posição, foram descritos três tipos de configurações: côncava, quando estava em posição lateral, convexa quando em posição medial e linear quando paralela ou se sobrepunha. Resultados: Das 240 pregas vestibulares, 158 eram côncavas, 41 convexas e 31 lineares. A forma côncava predominou nos dois grupos em relação às outras, porém as formas convexa e linear aumentaram no grupo disfonia. No feminino, a forma linear teve aumento significante no grupo disfonia, enquanto no masculino o aumento significante ocorreu na forma convexa. Conclusão: Existe diferença no comportamento da prega vestibular no grupo disfonia em relação à eufonia, sendo que esta diferença ocorre de forma diversa em relação aos gêneros.
\end{abstract}

\begin{abstract}
T he real participation of the vestibular fold during phonation mechanism is unknown. How the vestibular fold changes its configuration in phonation is unclear. To know this changes in the functional mechanism of vestibular fold will be helpful in the evaluation of the pathological conditions. Aim: The objective of this research was to study the configuration of the laryngeal vestibular fold during phonation (sustained emission of the I $\mu$ / sound) by comparing exams of individuals without vocal complaints (the euphonic group) with those with vocal complaints. Study Design: Transversal cohort simple study. Material and Method: 120 images of larynxes were analyzed, 60 of euphonic individuals and 60 dysphonic; constituting an equal number of individuals in relation to gender. The position of the free edge of the vestibular fold was identified, in relation to a straight line that unites its anterior and posterior insertions. Regarding this position, three types of configurations were described: concave, when it was in a lateral position, convex when it was in a medial position and linear when it overlaps. Results: Of the 240 vestibular folds, 158 were concave, 41 convex and 31 linear. The concave form was predominant in the two groups in relation to the other two, although the convex and linear forms increased in the dysphonic group. Analyzing the behavior of these forms in each gender we verified that in the female gender the linear form had a significant increase in the dysphonic group while in the masculine there was a significant increase in the convex form. Conclusion: We concluded that there existed a difference in the behavior of vestibular fold complaint in the dysphonic group in relation to euphony, and that this difference occurred in a diverse form in relation to gender.
\end{abstract}

\footnotetext{
${ }^{1}$ Professor Auxiliar em O torrinolaringologia e Cirurgia de Cabeça e Pescoço da Universidade Regional de Blumenau-FURB. Pós Graduando do Programa de Otorrinolaringologia e Cirurgia de Cabeça e Pescoço da Universidade Federal de São Paulo - UNIFESP.

${ }^{2}$ Professor, Livre Docente, Coordenador do Programa de Pós-Graduação em Otorrinolaringologia e Cirurgia de Cabeça e Pescoço da Universidade Federal de São Paulo - UNIFESP.

${ }^{3}$ Fonoaudióloga, Pós-Graduanda do Programa de Medicina Interna e Terapêutica e Especialização em Distúrbios da Comunicação Humana da Universidade Federal de São Paulo - UNIFESP.

${ }^{4}$ Médico Residente em Otorrinolaringologia da Universidade Federal de São Paulo - UNIFESP.

Tese apresentada à Universidade Federal de São Paulo - Escola Paulista de Medicina, para obtenção do título de Mestre em Ciências pelo Programa de Pós-Graduação em Otorrinolaringologia e Cirurgia de Cabeça e Pescoço. Orientador: Prof. Dr. Paulo Augusto de Lima Pontes

Aprovada no Comitê de Ética em Pesquisa da UNIFESP sob o Protocolo CEP No 0571/ 04.

Endereço para correspondência: Marcos Antônio Nemetz - Rua Heloy Dalsasso, 345 Blumenau SC 89030-230. Tel (0xx47) 326-3790 e 326-0417 - E-mail: mnemetz@terra.com.br

Artigo recebido em 18 de agosto de 2004. Artigo aceito em 11 de novembro de 2004.
} 


\section{INTRODUÇÃO}

A laringe é um órgão musculocartilaginoso, com múltiplas funções, situado na região infra-hióidea. Do ponto de vista filogenético, a principal função da laringe é a condução do ar na respiração seguida da de proteger as vias aéreas inferiores. Neste último, aciona-se a função esfincteriana, evitando a entrada de água e alimentos; por meio desta função, atua também não permitindo a saída de ar dos pulmões durante esforços fisiológicos, como o ato de defecar e o parto, por exemplo ${ }^{1}$. Do mecanismo esfinctérico da laringe participam de maneira ativa as pregas vestibulares e todo o vestíbulo. A musculatura envolvida no fechamento da luz laríngea pelas pregas vestibulares e pregas ariepiglóticas não é bem conhecida, mas provavelmente compreende a parte mais cranial do músculo tireoaritenóideo e os músculos ariepiglótico e tireoepiglótico ${ }^{2}$. O utros autores consideram que o fascículo transverso do músculo tireoaritenóideo forma o músculo da prega vestibular. Este, por sua vez, origina-se na cartilagem tireóidea e se dirige lateralmente em forma de leque superiormente à prega vestibular. A mobilidade da prega vestibular assim como as mudanças de forma do seio piriforme estariam relacionadas à elevação da prega vestibular pelo ligamento ariepiglótico ${ }^{3,4}$. A primeira descrição da musculatura do ventrículo laríngeo foi feita por Morgagni em 1723, onde são descritos dois ligamentos, um superior (prega vestibular) e outro inferior (prega vocal), sendo que neste o músculo tireoaritenóideo se projeta e apresenta feixes de fibras médias e superiores ${ }^{5}$. Quando o bolo alimentar passa pela via aérea, ocorre o fechamento da laringe que é acompanhado de um breve período de apnéia; isto dura uma fração de segundos, para logo em seguida a laringe se abrir para a respiração, enquanto o bolo alimentar entra no esôfago. Se, neste instante, algum resíduo alimentar permanecer no vestíbulo, será aspirado pelo movimento inspiratório que se segue à deglutição $0^{6-9}$. A pesar da importância do fechamento vestibular, acredita-se que a barreira mais efetiva contra a aspiração seja a nível glótico devido em primeiro lugar ao forte fechamento muscular reflexo promovido pelos adutores, e secundariamente ao formato triangular das pregas vocais (vistas frontalmente), com suas bordas livres direcionadas levemente em sentido cranial, o que constitui um mecanismo valvular passivo que dificulta a entrada de qualquer material na traquéia ${ }^{6}$. Uma correlação em sentido inverso pode ser feita quando se avalia a prega vestibular. Esta tem um formato valvular, com a borda livre voltada inferiormente, o que impõe maior resistência ao fluxo expiratório. Desta forma, quando há necessidade de aumento da pressão subglótica e traqueal (tosse, manobra de Valsava, por exemplo), esta disposição favorece 0 fechamento laríngeo ${ }^{10,11}$. A fonação é uma função adaptativa da laringe, já que ao longo do seu desenvolvimento esta não foi constituída para tal fim. Para a produção da fala contribuem três processos: o mecanismo de fole utilizando o ar oriundo dos pulmões, a geração do som na glote através da vibração das pregas vocais, a ressonância e a articulação deste som, as quais ocorrem no segmento supraglótico. Desta forma, não só a laringe, mas todo o sistema respiratório e também parte do deglutitório são importantes na produção e emissão da fala. 0 mecanismo de formação da fala na região glótica já está bastante claro. Sabe-se que a energia aerodinâmica gerada pelo fluxo expiratório é convertida em energia acústica pela vibração das pregas vocais. Para ocorrer esta vibração é necessário que forças antagônicas atuem sobre as pregas vocais, produzindo sua abertura e fechamento de modo harmônico e sucessivo. A força de abertura é representada pela pressão subglótica. Já a mioelasticidade das pregas vocais relacionadas à atividade neuromuscular da laringe, e 0 efeito de Bernoulli constituem as principais forças de fechamento. Quanto mais móvel e elástica a prega vocal, mais intenso é o fechamento provocado pelo efeito de Bernoulli. Do ponto de vista ultra-estrutural, as pregas vocais são organizadas em camadas com propriedades estruturais e mecânicas diferentes, sendo mais flexíveis na superfície, tornandose mais rígidas em direção ao músculo vocal o que é essencial para o adequado movimento vibratório desta prega vocal ${ }^{12-14}$. O bserva-se participação das pregas vestibulares durante o mecanismo da emissão vocal, com mudanças evidentes de posição e forma durante este processo, porém pouco ou quase nada se conhece sobre o significado desta participação. Na literatura médica referente à fisiologia da produção vocal, quase nada existe, referindo-se ao real papel desempenhado por estas estruturas neste complexo mecanismo, onde, e como se iniciam estes movimentos ativos que mudam sua forma e contorno, sendo toda a atenção voltada à importância do controle neuromuscular e para as propriedades viscoelásticas das pregas vocais. A prega vestibular está relacionada com a formação do terceiro formante. Os formantes são faixas de freqüências que caracteristicamente contêm centróides de energia $a^{15}$. As freqüências dos formantes dependem do comprimento e do formato do trato vocal. 0 comprimento é definido como a distância entre a glote e a abertura dos lábios. 0 som glótico inicial é modificado pela ressonância. 0 sistema de ressonância humano depende diretamente da configuração geométrica tridimensional do trato vocal e das paredes ${ }^{16}$. 0 movimento de um dos articuladores geralmente afeta a freqüência de todos os formantes. As freqüências do primeiro formante são particularmente sensíveis às mudanças no abaixamento da mandíbula. Um aumento no abaixamento da mandíbula tende a aumentar a freqüência do primeiro formante. 0 segundo formante é particularmente sensível às mudanças de posição da língua. Quando a língua realiza um ponto de constrição na parte anterior do trato vocal, a freqüência do segundo formante é mais alta. Se a língua realiza um ponto de constrição na região velar, a freqüência do segundo formante é mais baixa. 0 segundo formante atinge seu valor mais baixo quando a língua encosta-se ao véu palatino e os lábios estão protraídos, como na emissão da vogal / u/ . 0 terceiro formante está relacionado à ressonância 
da região acima das pregas vocais, formada pelos ventrículos laríngeos, pregas ariepiglóticas e pregas vestibulares ${ }^{17}$. Sabemos que este formante é particularmente sensível às posições da ponta da língua, ou mais especificamente ao tamanho da cavidade que se forma imediatamente atrás dos incisivos inferiores. Se esta cavidade for ampla, a freqüência do terceiro formante tende a ser baixa ${ }^{18}$. O s valores médios das freqüências dos formantes encontrados para mulheres falantes nativas do português brasileiro foram para o primeiro, segundo e terceiro formantes da vogal oral /a/ respectivamente 956, 1634 e $2721 \mathrm{~Hz}$; da vogal oral /i/ respectivamente, 425, 2984 e $3668 \mathrm{~Hz}$ e da vogal oral /u/, 462, 1290 e $2528 \mathrm{~Hz}$, com grande desvio padrão entre os indivíduos analisados.(19). Anatomicamente, as pregas vestibulares inseremse na parte mais alta do ângulo interno da cartilagem tireóidea seguindo daí horizontalmente para trás, indo se fixar na face interna da cartilagem aritenóidea. Tem o formato de duas lâminas planas com duas faces e duas bordas. A face superior, inclinada para baixo, corresponde à porção supraglótica da laringe. A face inferior segue o mesmo sentido e forma a parede interna do ventrículo. A borda externa continua-se com a prega ariepiglótica, já a interna ou borda livre acompanha a rima glótica. A estrutura da prega vestibular é formada pelo ligamento tireoaritenóideo superior, que é uma lâmina fibroelástica ${ }^{20-23}$. A camada subepitelial das pregas vestibulares possui mais glândulas $\left(128 / \mathrm{cm}^{2}\right)$, quando comparada à região glótica $\left(13 / \mathrm{cm}^{2}\right)$, daí sua importância na lubrificação do epitélio laríngeo e nas suas propriedades viscoelásticas. As pregas vestibulares durante o mecanismo fonatório tensionam fortemente as cartilagens aritenóides e simultaneamente tracionam para cima as pregas ariepiglóticas, desta forma alargando o ventrículo e proporcionando espaço para uma maior amplitude de vibração das pregas vocais ${ }^{24}$. Distúrbios fonatórios associados à estrutura das pregas vestibulares são relatados na literatura médica como disfonia ventricular ou disfonia vestibular25-27. Este tipo de disfonia pode ocorrer como uma compensação devido a alterações anatômicas ou fisiológicas da laringe ou como uma hipertrofia isolada da prega vestibular ${ }^{28}$. Nas paralisias da prega vocal, dependendo da posição da prega vocal paralisada, poderá haver medialização da prega vestibular contralateral. Nas pregas paralisadas em posição mediana ocorre medialização da prega vestibular em $59.5 \%$ dos casos, já naquelas em posição lateral isto acontece em $77,7 \%$ das vezes. Isto pode ocorrer devido a um ajuste compensatório da prega vestibular devido à coaptação glótica insuficiente, ou seja, na medida que a fenda glótica aumenta, maior é a tentativa de compensação exercida pelo vestíbulo no sentido de desenvolver uma fonte sonora adiciona|29-31. Parte-se então do pressuposto que o mesmo pode ocorrer em outras condições que alterem a fenda glótica. A limitação dos estudos relativos à função das pregas vestibulares no mecanismo vocal justifica-se pela raridade de trabalhos que enfoquem este tema. Entendemos que o conhecimento da participação das pregas vestibulares na fisiologia laríngea possa ter importante aplicação prática, pois permitirá avaliar meIhor o comprometimento funcional em condições patológicas, o que auxiliará na definição de estratégias para 0 adequado tratamento.

\section{OBJETIVO}

Verificar se existe diferença na forma da prega vestibular em um grupo de pacientes com queixa vocal quando comparado a um grupo de pacientes sem queixa vocal, considerando-se também o gênero.

\section{MATERIAL E MÉTODO}

O material deste estudo constou de cento e vinte gravações de imagens de laringes obtidas por meio de videolaringoscopias realizadas no Instituto da Laringe - INLAR, em São Paulo. Essas laringes pertenciam a indivíduos adultos acima de dezoito anos, e abaixo de 45 anos distribuídas igualmente entre indivíduos masculinos e femininos, sendo sessenta sem alterações de voz, que constituíram grupo eufonia e sessenta com alterações, que constituíram o grupo disfonia. Cada 10 indivíduos com queixa de voz do gênero feminino possuíam um dos três tipos de alterações: nódulo vocal, paralisia unilateral de prega vocal e alteração estrutural mínima (cisto de prega vocal ou sulco estria). Os do gênero masculino, à semelhança do feminino possuíam: granuloma, paralisia unilateral de prega vocal e alteração estrutural mínima. As pregas vestibulares foram analisadas individualmente, 0 que resultou em 120 pregas vestibulares em cada um dos dois grupos. Não foi realizado nenhum procedimento específico com os pacientes para este estudo, por ter-se tratado de imagens de arquivo. 0 exame de telelaringoscopia foi realizado sob anestesia tópica com Lydocaína ${ }^{\circledR} 10 \%$ spray com o paciente sentado e de boca aberta, com a língua protraída e mantida por pinçamento digital, envolvida em gaze. Utilizouse telescópio Machida ${ }^{\circledR}$ de $70^{\circ}$ e sistema de vídeo convencional com microcâmera Panasonic ${ }^{\circledR} \mathrm{KS152}$. Durante a avaliação, o paciente foi orientado a respirar pela boca, sem esforço, e a emitir a vogal // sustentada, em intensidade e altura próximas a uma emissão habitual. As imagens foram transferidas para um computador AMD Atlon XP $16001.6^{\circledR}$, com sistema operacional Windows $2000^{\circledR}$, e digitalizadas utilizando o programa de captura de imagens Adobe Premiere ${ }^{\circledR}$ com placa para captura de vídeo Pinnacle ${ }^{\circledR}$ DC 1000. Destas imagens foi retirado para cada paciente apenas um quadro durante a fonação do // sustentado, desconsiderando-se 0 início e o fim da emissão.

$\mathrm{Na}$ seleção das imagens, feitas ao acaso no arquivo, foram considerados fatores de exclusão:

- Presença de lesões nas pregas vocais à exceção dos nódulos, granulomas, paralisia ou alteração estrutural mínima tipo cisto ou sulco estria; 
- Impossibilidade de localização da inserção da prega vestibular quer sob visão direta através da laringoscopia ou por inferência através da análise dinâmica quadro a quadro;

- Má qualidade da imagem arquivada ou presença de secreções com impossibilidade de se definir os limites das diversas estruturas;

- Imagens em que a emissão ocorreu com a presença de reflexo nauseoso.

Estas imagens foram analisadas no computador para se definir os parâmetros de referência. As estruturas foram identificadas pelas diferenças de coloração e/ ou de suas respectivas intensidades. Três pontos anatômicos foram identificados para se chegar na definição da conformação de PV mais extensa, a saber: anterior, posterior, e de deslocamento (Figura 1).

Ponto Anterior (A) - corresponde à inserção ante-

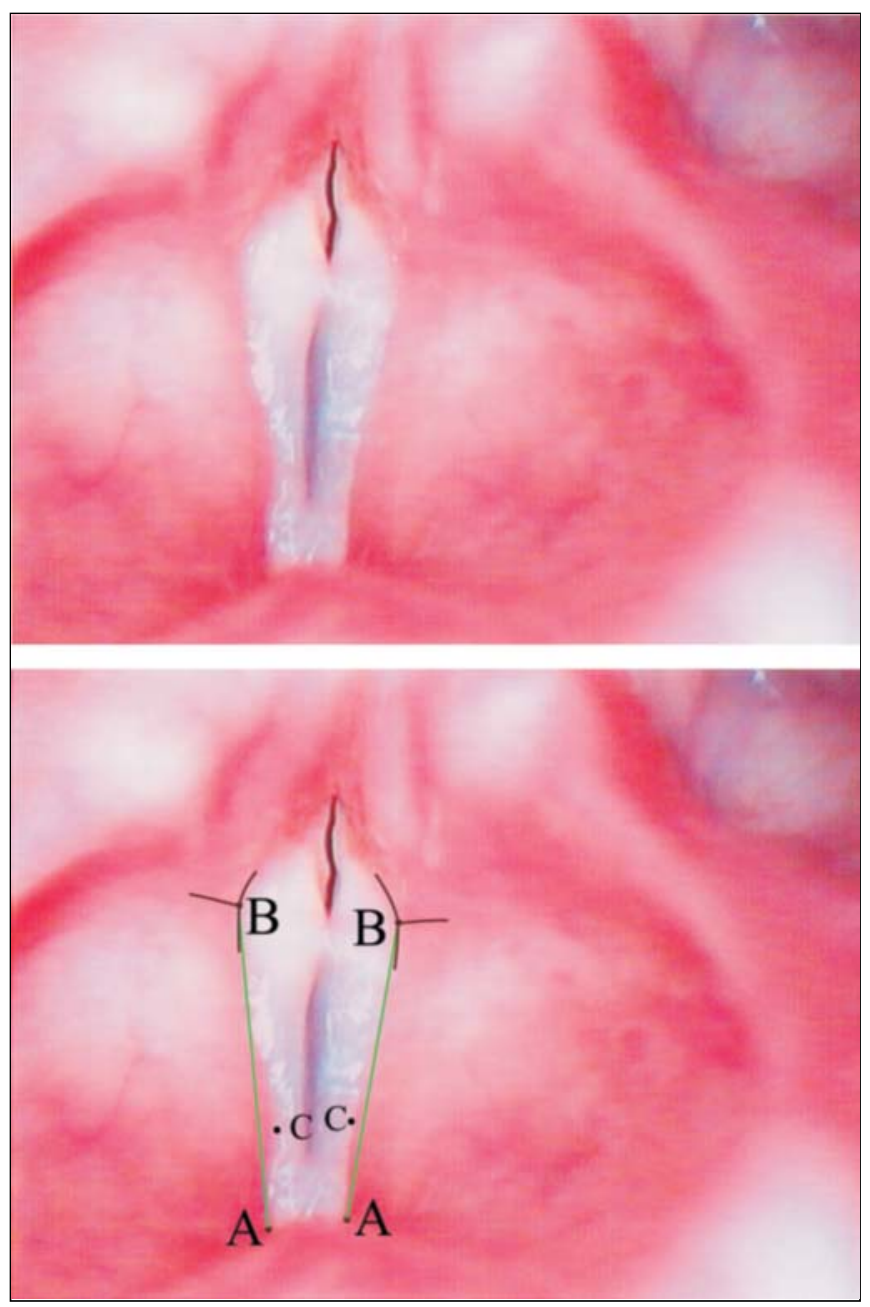

Figura 1. Superior - Imagem por telelaringoscopia de laringe do gênero masculino durante a emissão da vogal/e/ e portador de sulco estria maior com pregas vestibulares de forma convexa. Inferior mesma imagem com os pontos, as linhas de intersecção de definição dos pontos $B$ (pretas) e as retas $A B$ (verdes) de referência. rior da borda da prega vestibular, próxima ao ângulo interno da cartilagem tireóidea (Figura 1). Ela é variável, podendo estar junto ao pecíolo da epiglote ou afastado desta. O utras vezes, antes de atingir esta região, a borda se dicotomiza e forma um triângulo; nestes casos considerou-se 0 vértice da abertura como o ponto de inserção (Figura 1).

Ponto Posterior (B) - é onde termina posteriormente a borda livre da prega vestibular. É identificado utilizando como referência a superfície da região aritenóidea, as superfícies das pregas vestibulares e a superfície da face vestibular da prega vocal. A união destas três superfícies forma três linhas confluentes, cujo ponto de intersecção denominamos ponto posterior B: uma linha lateral entre a face mais escura da região aritenóidea com a superfície mais clara da prega vestibular, uma medial posterior que corresponde à junção da superfície mais escura da região aritenóideia contra a superfície mais clara e brilhante da prega vocal e uma medial anterior formada pelo contraste en-
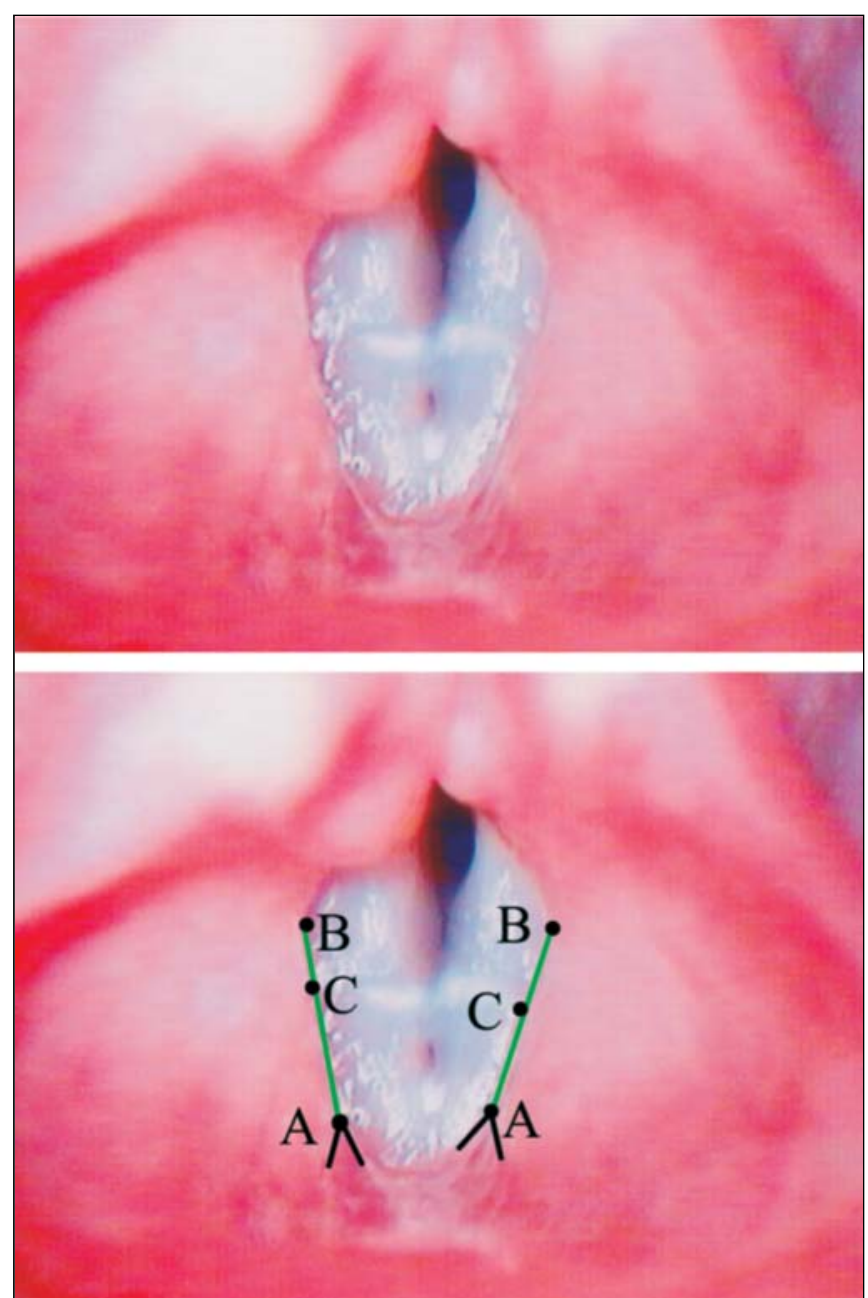

Figura 2. Superior - Imagem por telelaringoscopia de laringe do gênero feminino durante a emissão da vogal /e/ portadora de nódulo vocal com pregas vestibulares de forma linear. Inferior - mesma imagem com os pontos (pretos), linhas de definição dos pontos $A$ (pretas) e as retas $A B$ (verdes) de referência. 
tre a borda da prega vestibular e a superfície da prega vocal. Na determinação desta última, o contraste é dado e fundamentalmente pela cor e não pela intensidade. (Figura 3).

A linha que une esses dois pontos é designada $A B$

Quando estes dois pontos ou um deles não ficavam expostos na telelaringoscopia, observava-se o movimento de adução quadro a quadro e sendo possível inferir a posição dessas inserções, a imagem era considerada apta para a análise.

Ponto de Deslocamento (C) é o ponto que corresponde ao maior deslocamento da prega vestibular em relação à linha $A B$ (Figuras 1 a 4).

De acordo com a posição do ponto $C$ em relação à linha $A B$, definimos três tipos de formas da borda livre da prega vestibular:

- Formaconvexa- quando o ponto $\mathrm{C}$ da borda livre da prega

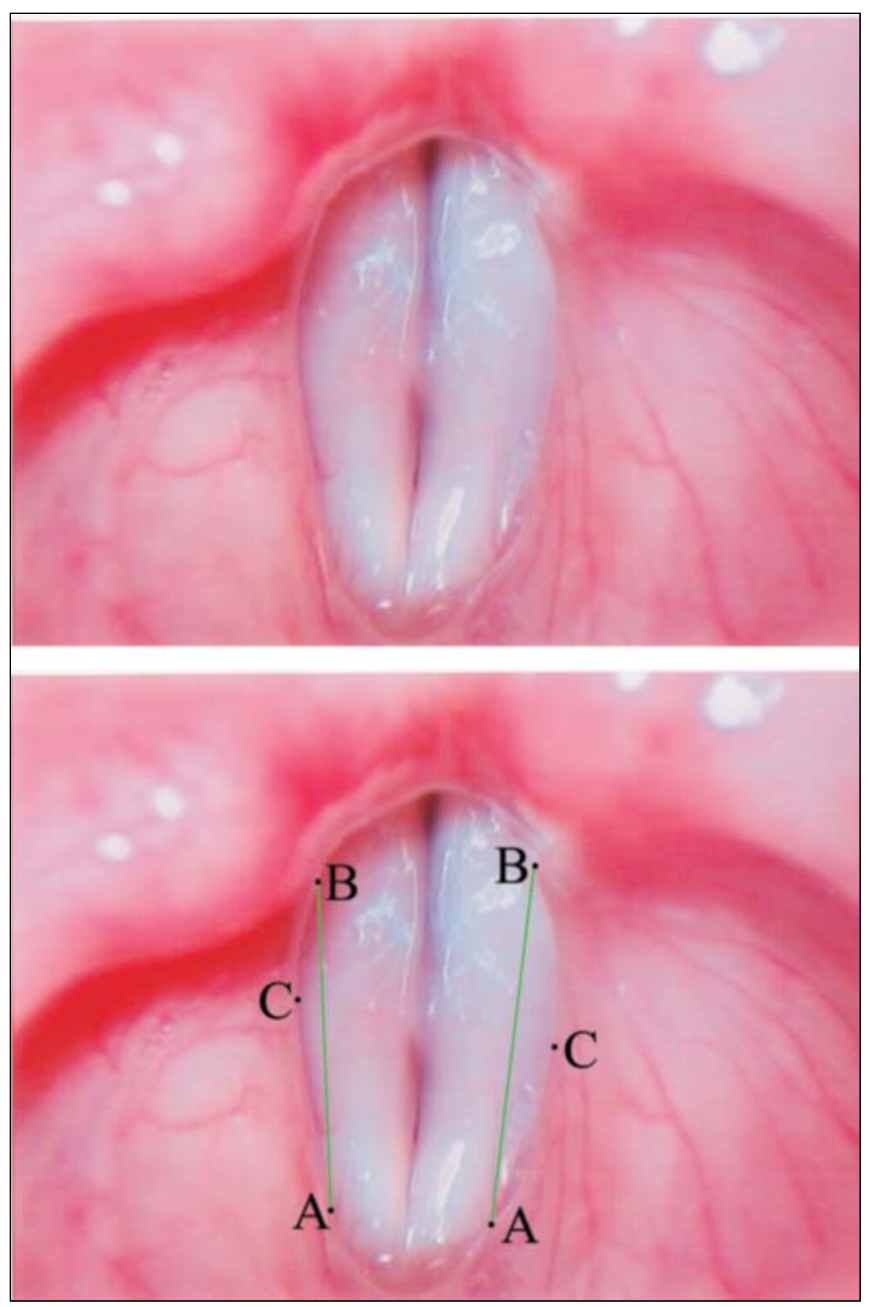

Figura 3. Superior - Imagem por telelaringoscopia de laringe de indivíduo do gênero feminino durante a emissão da vogal /e/ e portadora de sulco estria menor com pregas vestibulares de forma côncava. Inferior - mesma imagem com os pontos e as retas AB de referência. vestibular localiza-se medialmente à reta $A B$ (Figura 1 ).

- Forma côncava - quando o ponto $C$ da borda livre da prega vestibular encontra-se situado lateralmente à reta AB (Figura 3).

- Formalinear - quando o ponto $C$ se sobrepõe ou está muito próximo à linha $A B$ (Figura 2).

Q uando a borda livre da prega vestibular tem parte lateral e parte medialmente situada em relação à reta $A B$ (sinusoidal), é considerada côncava ou convexa de acordo com a posição do ponto C (Figura 4).

Análise estatística: utilizou-se inicialmente uma análise não paramétrica e na presença da diferença o estudo paramétrico:

- Teste de duas amostras para proporções (teste t para duas amostras de variáveis equivalentes e diferentes, e 0 teste t de observações pareadas);

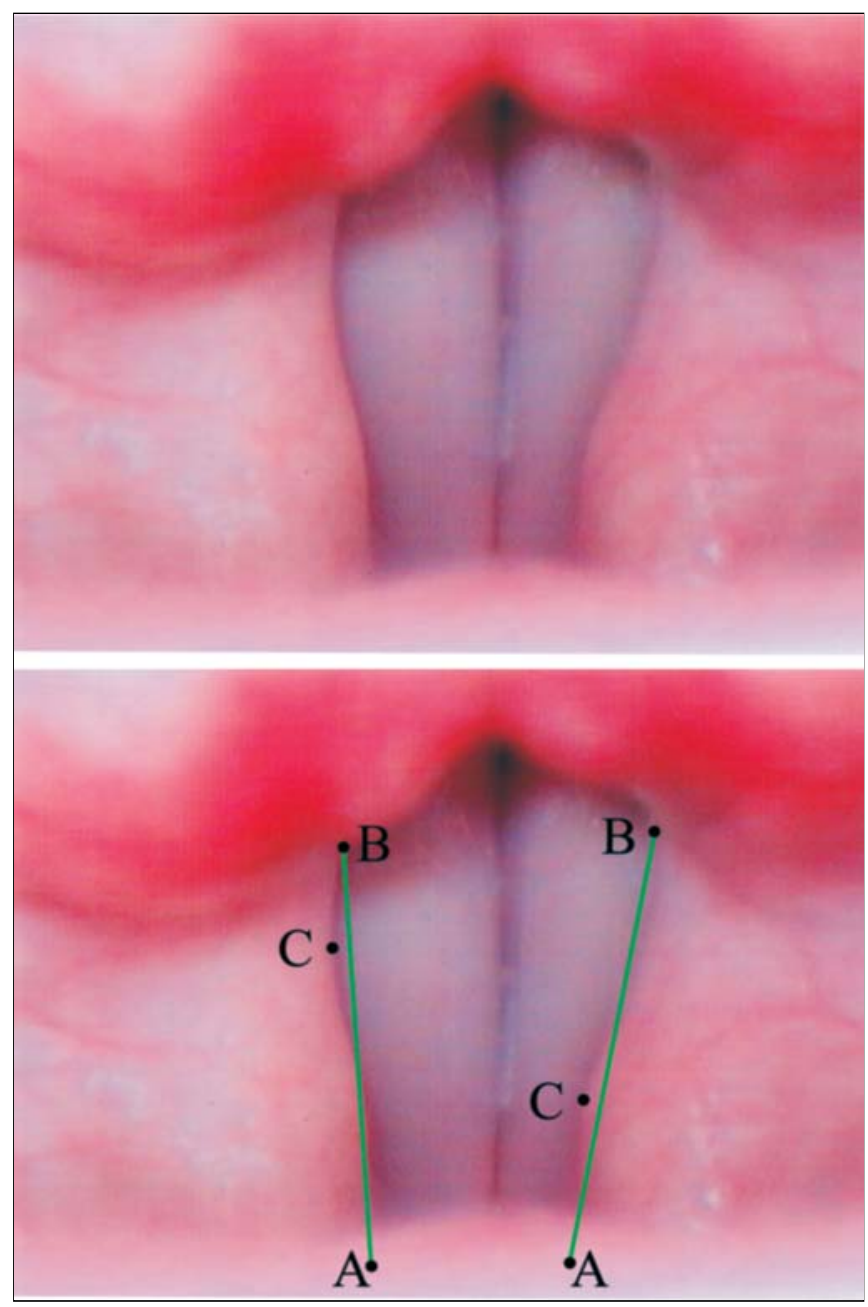

Figura 4. Superior - Imagem por telelaringoscopia de laringe de indivíduo do gênero masculino durante a emissão da vogal /e/, eufônico, com pregas vestibulares sinusoidais, sendo a direita côncava e a esquerda convexa. Inferior - mesma imagem com os pontos e as retas $A B$ de referência. 
- Teste de aderência (qui-quadrado) - para freqüências do mesmo grupo. Os resultados significantes foram identificados com asteriscos.

\section{RESULTADOS}

Os resultados serão apresentados em forma de tabelas.

\section{DISCUSSÃO}

Os resultados mostram que a forma côncava das pregas vestibulares à fonação é a forma padrão, tanto em relação aos gêneros quanto em relação à presença ou não da disfonia (Tabelas 1 e 3). Contudo, comparando os resultados da Tabela 2 , verificamos que no grupo disfonia a redução do número da forma côncava resultou do aumento tanto da forma convexa quanto da linear. Configuradas as diferenças em relação à disfonia, a pergunta que surge é se esta diferença ocorreu no mesmo sentido em ambos os gêneros. A Tabela 4 mostra que no gênero masculino houve aumento significativo da forma convexa no grupo disfônico, enquanto no feminino este aumento ocorreu na forma linear. Podemos supor, pelos nossos resultados, que quando a fonação se faz de forma harmonio$\mathrm{sa}$, as pregas vestibulares se comportam de forma semelhante em ambos os gêneros, contudo quando ocorrem dificuldades, elas se comportam de modo diferente quanto à forma, porém de igual modo no sentido do deslocamento, isto é, de lateral para medial. A pergunta que se segue é: por que as pregas vestibulares das mulheres se deslocaram de modo diferente quanto à forma em relação às dos homens diante da disfonia? Não temos a resposta neste sentido, porém podemos supor que ela está na diferença de configuração anatômica da laringe que existe entre os gêneros e que clinicamente se traduz pela diferença da proporção glótica. Sabemos por estudos anteriores ${ }^{33}$ que na proporção glótica baixa, como ocorre nas laringes de padrão feminino, a aproximação das aritenóides não é completa, o que resulta na presença da fenda posterior à fonação nas mulheres e sendo completa nos homens, nestes fenda posterior é rara ${ }^{32}$. É possível fazermos a hipótese de que esta diferença de configuração anatômica também se relacione com a forma das pregas vestibulares de acordo com o gênero na disfonia; um eventual esforço fonatório que agiria medializando a prega vestibular, resultaria em conformações diferentes das pregas vestibulares entre os gêneros. No gênero masculino esta medialização seria favorecida como ocorre com as aritenóides e, portanto, a forma convexa mais predominante no gênero masculino corresponderia à da forma linear predominante no feminino. Se esta hipótese em estudos posteriores vier a ser confirmada, a simples observação da configuração da prega vestibular poderá ser um valioso sinal semiológico que, somado aos demais sinais, poderá nos auxiliar no diagnóstico da presença de esforço durante a fonação, mesmo antes de se apresentar alterações na qualidade vocal. Além do possível valor
Tabela 1. Distribuição numérica das pregas vestibulares, segundo a configuração nos grupos eufonia e disfonia com os gêneros.

\begin{tabular}{lccccc}
\hline Forma & \multicolumn{2}{c}{ grupo eufonia } & \multicolumn{2}{c}{ grupo disfonia } & Total \\
& Feminino & Masculino & Feminino & Masculino & \\
\hline Côncava & $51^{*}$ & $49 * *$ & $36 * * *$ & $32 * * * *$ & 168 \\
Convexa & 08 & 02 & 10 & 21 & 41 \\
Linear & 01 & 09 & 14 & 07 & 31 \\
\hline Total & 60 & 60 & 60 & 60 & 60 \\
\hline$* \chi^{2}=14,68 p=0,00065$ g.l. $=2$ & & & \\
$* * \chi^{2}=8,41 \mathrm{p}=0,01493$ g.l. $=2$ & \\
$* * * \chi^{2}=14,08 p=0,00088$ g.l. $=2$ \\
$* * * * \chi^{2}=19,51 \mathrm{p}=0,00006$ g.l. $=2$
\end{tabular}

Tabela 2. Distribuição numérica e percentual das pregas vestibulares, segundo a configuração em relação aos grupos eufonia e disfonia.

\begin{tabular}{lcccccc}
\hline Forma & \multicolumn{2}{c}{ grupo eufonia } & \multicolumn{2}{c}{ grupo disfonia } & \multicolumn{2}{c}{ Total } \\
& $\mathrm{N}$ & $\%$ & $\mathrm{~N}$ & $\%$ & $\mathrm{~N}$ & $\%$ \\
\hline Côncava & 100 & 83,3 & 68 & 56,6 & 168 & 70,0 \\
Convexa & 10 & 8,3 & $31^{*}$ & 25,8 & 41 & 17,0 \\
Linear & 10 & 8,3 & $21^{*}$ & 17,5 & 31 & 12,9 \\
\hline Total & 120 & 100 & 120 & 100 & 240 & 100 \\
\hline$\chi^{2}=20,75 p<0000,3$ g.l. $=2$ &
\end{tabular}

Tabela 3. Distribuição numérica e percentual da forma côncava da prega vestibular nos grupos eufonia e disfonia em relação aos gêneros

\begin{tabular}{lcccccc}
\hline Gênero & \multicolumn{2}{c}{ grupo eufonia } & \multicolumn{2}{c}{ grupo disfonia } & \multicolumn{2}{c}{ Total } \\
& $\mathrm{N}$ & $\%$ & $\mathrm{~N}$ & $\%$ & $\mathrm{~N}$ & $\%$ \\
\hline Masculino & 49 & $49 \%$ & 32 & $47,06 \%$ & 81 & $48,71 \%$ \\
Feminino & 51 & $51 \%$ & 36 & $52,94 \%$ & 87 & $51,79 \%$ \\
\hline Total & 100 & $100 \%$ & $68 *$ & $100 \%$ & 168 & $100 \%$ \\
\hline$\chi^{2}=0,06 \mathrm{p}=0,805 \mathrm{~g} . \mathrm{l.}=1$
\end{tabular}

Tabela 4. Distribuição numérica e percentual da forma convexa da prega vestibular nos grupos eufonia e disfonia em relação aos gêneros

\begin{tabular}{lcccccc}
\hline Gênero & \multicolumn{2}{c}{ grupo eufonia } & \multicolumn{2}{c}{ grupo disfonia } & \multicolumn{2}{c}{ Total } \\
& $\mathrm{N}$ & $\%$ & $\mathrm{~N}$ & $\%$ & $\mathrm{~N}$ & $\%$ \\
\hline Masculino & 02 & $20 \%$ & $21^{*}$ & $67,74 \%$ & 23 & $56,10 \%$ \\
Feminino & 08 & $80 \%$ & 10 & $32,26 \%$ & 18 & $43,90 \%$ \\
\hline Total & 10 & $100 \%$ & 31 & $100 \%$ & 41 & $100 \%$ \\
\hline
\end{tabular}

Tabela 5. Distribuição numérica e percentual da forma linear da prega vestibular nos grupos eufonia e disfonia em relação aos gêneros.

\begin{tabular}{lcccccc}
\hline Gênero & \multicolumn{2}{c}{ grupo eufonia } & \multicolumn{2}{c}{ grupo disfonia } & \multicolumn{2}{c}{ Total } \\
& $\mathrm{N}$ & $\%$ & $\mathrm{~N}$ & $\%$ & $\mathrm{~N}$ & $\%$ \\
\hline Masculino & 09 & $90 \%$ & 07 & $33,33 \%$ & 16 & $51,61 \%$ \\
Feminino & $01 *$ & $10 \%$ & $14 *$ & $66,67 \%$ & 15 & $48,39 \%$ \\
\hline Total & 10 & $100 \%$ & 21 & $100 \%$ & 31 & $100 \%$ \\
\hline$\chi^{2}=8,71 \mathrm{p}=0,000316$ g.l. $=1$ & & &
\end{tabular}


semiológico da configuração da prega vestibular, poderíamos também relacioná-la com aspectos fisiológicos que envolvem 03 o e 0 40 formantes do mesmo modo que o formante do cantor. Existem consideráveis diferenças entre as vozes na fala coloquial e aquelas no canto de ópera ou de concertos. Estas diferenças não são apenas na expressão musical como também na obtenção de maior potência vocal na presença dos sons da orquestra. Este "aumento de potência" está relacionado com o aparecimento de um reforço no envelope do espectro acústico na região de $2-3 \mathrm{kHz}$ coincidindo com a faixa dos 30 e 40 formantes como se houvesse uma fusão de ambos; nos cantores masculinos este reforço é bem evidente e é conhecido como o formante do cantor. Para que ocorra a fusão do 3 e e 4ํformantes há necessidade de três ocorrências simultâneas ${ }^{17,18}$ :

\section{A secção transversal da faringe na região da laringe seja} mais de seis vezes a área da abertura da laringe;

2. Abaixamento da laringe;

3. Aumento do ventrículo laríngeo.

Considerando que a parede lateral do ventrículo é fixa e que seu assoalho à fonação é constituído pelas pregas vocais em coaptação, é evidente que o aumento do ventrículo só poderá ocorrer pela mobilização da prega vestibular em direção medial ou assumindo a forma convexa como ocorre no homem, satisfazendo o item 3. Por outro lado, deste comportamento da prega vestibular resultará a redução da luz laríngea na região da rima vestibular, o que elevará a relação entre a secção transversal da faringe na região da laringe e a área da luz laríngea, o que também satisfaz o requisito do item 1 para a fusão do 30 e 4 o formantes. Assim, podemos inferir que esta característica anátomo-funcional favorece a formação do formante do cantor no gênero masculino.

\section{CONCLUSÃO}

Diante dos nossos dados, podemos concluir que houve mudança no comportamento da prega vestibular nos grupos de pacientes com disfonia em relação ao dos sem queixa vocal. No sexo masculino a modificação ocorreu com aumento significativo da forma convexa, enquanto que no sexo feminino 0 aumento se fez na forma linear, porém em todas as situações a forma côncava foi predominante.

\section{REFERÊNCIASBIBLIOGRÁFICAS}

1. Hirano $M$, Sato K. Histological color atlas of the human larynx. San Diego: Singular; 1993. p.1-36.

2. Imamura $R$, Yoshida $Y$, Fukunaga $H$, Nakashima $T$, Hirano $M$. Thyroaytenoid muscle: functional subunits based on morphology and fiber typing in cats. Ann Otol Rhinol Laryngol 2001; 110: 158-67.

3. Guida HL. Estudo morfológico e histoquímico da prega vestibular em laringes humanas. Botucatu; 2001. Tese (Mestrado em Ciências Biológicas). Instituto de Biociências, Universidade Estadual Paulista.
4. Canalis RF. Laryngeal ventricle historical features. Ann Otol Rhinol Laryngol 1980; 89: 184-7.

5. Imamura R, Tsuji DH, Sennes LU. Fisiologia da laringe. In: Campos CAH; Costa HO. Tratado de otorrinolaringologia. São Paulo: Roca; 2002. p. 743-50.

6. Negus VE. The mecanism of the larynx. Laryngoscope 1957; 67: 961-86.

7. Negus VE. The comparative anatomy and physiology of the larynx. New York: Hafner; 1962. p. 1-230.

8. Pressmann JJ, Kelemen G. Phsysiology of the larynx. Rev physiol 1955; 35: 506-54.

9. Hiroto I. The mechanism of phonation its patho-physiology aspects. Otol-rhino-laryngol Clinic 59: 229-91, 1966.

10. Titze IR. In: Fujimura O. Vocal fold physiology: voice production, mechanisms and functions. New York: Raven Press; 1988. p. 227-38.

11. Hirano M. Neurolaryngology: recents advances. San Diego: Singular; 1991. p.209-30.

12. Isshiki N, Tsuji DG, Sennes LU. Tireoplastias. São Paulo: Bios 1999; p.31-7.

13. Van Den Berg J, Tan TS. Results of experiments with human larynxes. Pract Otorhinolaryngol 1959; 21: 425-50.

14. Black JW. The quality of a spoken vowel. Arch. Speech 1937; 2: 7-27.

15. Speacks CE. Introduction to sound. San Diego: Singular; 1992. $308 \mathrm{p}$.

16. Titze IR, Story BH. Acoustic interactions of the voice source with the lower vocal tract. J Acoust Soc Am 1997; 101: 2234-43.

17. Sundberg J. The source spectrum of professional singing. Folia Phonitr 1973; 5: 71-90.

18. Sundberg J. Articulatory in introduction of the "singing formant". JASA 1974; 55: 838-44.

19. Behlau MS, Pontes PAL, Tosi O, Ganança MM. Análise espectrográfica dos formantes das vogais do português brasileiro. ACTA WHO 1988; 7: 74-85.

20. Testut L, Latarjet M. Tratado de anatomia humana. Barcelona: Salvat 1951; 3: 881-32.

21. Gardner E, Gray DJ, O'Rahilly R. Anatomia: estudo regional do corpo humano. 4a ed. Rio de Janeiro: Guanabara Koogan; 1988. p.738-49.

22. Paparella MM, Shumrick DA. Otolaryngology. $2^{\underline{a}}$ ed. Buenos Aires: Editorial Médica Panamericana; 1982. p.364-7.

23. Berendes J, Link R, Zöllner F. Tratado de otorrinolaringologia. Barcelona: Editorial Científico-Médica 1970; 2: 793-809.

24. 24.Von Doersten PGET. Ventricular dysphonia: a profile of 40 casos. Laryngoscope 1992; 102: 1296-301.

25. Fink BR.Vocal Fold mechanism of the human larynx. Acta Otolaryng 1974; 78: 124-8.

26. Behlau M, Pontes PAL. As chamadas disfonias espasmódicas: dificuldades de diagnóstico e tratamento. Rev Bras Otorrinolaringol 1997; 63(Suppl):1-27.

27. Pinho SMR, Pontes PAL, Gadelha MEC, Biasi N. Vestibular vocal fold behavior during phonation in unilateral vocal fold paralysis. J. Voice 1999; 13:36-42.

28. Eckberg 0 . Closure of the laryngeal vestibule during deglutition. Acta Otolaryngol 1982; 93: 123-9.

29. Ruyz DMCF. Paralisias laríngeas unilaterais em diferentes faixas etárias e suas correlações com a etiologia e configuração laríngea. Botucatu, 2003. Tese (Doutorado em Ciências Biológicas). Instituto de Biociências, Universidade Estadual Paulista.

30. Koufman JA, Postma GN, Cummins MM, Blalock PD. Vocal fold paresis. Otolaryngol Head Neck Surg 2000; 122: 537-41.

31. Hirano M, Kiyokawa K, Kurita S. Laryngeal muscles and glottal shaping. In: Fujimura O. (ed.) Vocal fold physiology. Voice production, mechanisms and functions. New York: Raven Press; 1988. p. 249-64.

32. Pontes $P$, Behlau M, Kyrillos L. Configurations et rapport glottique: un essai pour compendre la fenta glottique posterieure. R. Laryngol 1994; 115: 261-6.

33. Pontes P, Kyrillos L, Behlau M, De Biase N. Vocal Nodules and Laryngeal Morphology. J Voice 2002; 16: 408-14. 